\title{
Short Communication EBV-associated gastric carcinoma in high- and low-incidence areas for nasopharyngeal carcinoma
}

\author{
T Boysen', M Mohammadi' ${ }^{2}$, M Melbye', S Hamilton-Dutoit ${ }^{3}$, B Vainer ${ }^{2}$, AV Hansen', J Wohlfahrt' \\ and J Friborg*,I
}

'Department of Epidemiology Research, Statens Serum Institut, Artillerivej 5, 2300 Copenhagen S, Denmark; ${ }^{2}$ Department of Pathology, Rigshospitalet, Copenhagen University Hospital, Blegdamsvej 9, 2100 Copenhagen O, Denmark; ${ }^{3}$ Institute of Pathology, Aarhus University Hospital, Norrebrogade 44, 8000 Aarhus C, Denmark

BACKGROUND: Approximately 10\% of gastric carcinomas are associated with Epstein-Barr virus (EBV). The Inuit in Greenland have a high incidence of EBV-associated nasopharyngeal carcinoma.

METHODS: We conducted a population-based case-control study comparing gastric carcinomas in Greenland and in Denmark. RESULTS: The prevalence rate of EBV-associated gastric carcinomas was $8.5 \%$ in both populations.

CONCLUSION: The findings of this study argue against a general susceptibility to EBV-associated carcinomas among the Inuit. British Journal of Cancer (2009) I 0 I, 530-533. doi:I0.1038/sj.bjc.6605 I68 www.bjcancer.com

Published online 14 July 2009

(c) 2009 Cancer Research UK

Keywords: Epstein-Barr virus; gastric carcinoma; nasopharyngeal carcinoma

Approximately $8-10 \%$ of gastric carcinomas worldwide are associated with Epstein-Barr virus (EBV) infection, making gastric carcinomas the most frequent EBV-associated malignancy (Burgess et al, 2002; Hjalgrim et al, 2008). The involvement of EBV in gastric carcinomas is based on the specific presence of viral gene products such as EBV-encoded small RNA (EBER) in tumour cells, but not in the surrounding non-neoplastic epithelium, and the presence of clonal EBV in tumour cells. (Shibata and Weiss, 1992; Imai et al, 1994). However, the precise aetiological role of EBV in this cancer and the mechanisms leading to EBV infection of the gastric epithelium are still unknown.

Undifferentiated nasopharyngeal carcinoma (NPC) is rare in most parts of the world, but is frequent in Southern China, North Africa and among the Inuit in the Arctic. The association between EBV and undifferentiated NPC has been known for the last 40 years, and is now firmly established (IARC working group, 1997; Hjalgrim et al, 2008). A study among the Chinese indicated that EBV-associated gastric carcinomas are more common in high- as compared with low-incidence regions of NPC, suggesting that these share risk factors (Hao et al, 2002). Not only are the Greenlandic Inuit an NPC high-risk population but they also have the world's highest incidence of salivary gland carcinomas, the majority being of EBV-associated lymphoepithelial carcinoma type (Hamilton-Dutoit et al, 1991; Friborg et al, 2003). Remarkably, the incidence of gastric carcinomas among the Inuit is increasing in contrast to the pattern seen elsewhere; the reasons for this increase are unknown (Friborg et al, 2003; Parkin et al, 2005; Alberts et al, 2006).

*Correspondence: Dr J Friborg; E-mail: jfr@ssi.dk

Revised 4 June 2009; accepted 8 June 2009; published online I 4 July 2009
To determine whether the proportion of EBV-associated gastric carcinomas differs in the Inuit compared with that in the Danish population, we conducted a population-based comparative study of patients with gastric carcinoma in Greenland and Denmark.

\section{MATERIALS AND METHODS}

The proportion of EBV-associated gastric carcinomas in Greenland and Denmark was examined in a case-control design using the Danish Cancer Registry (DCR), the Danish Civil Registration System and the Danish Pathology Database. All individuals in Denmark and Greenland are registered in the Civil Registration System (CRS). The CRS was established in Denmark on 1 April 1968 and in Greenland on 1 June 1972, when all persons alive and resident were registered and assigned a unique personal identification number (the person number). Information on cancer was retrieved from the DCR. Reporting of cancer cases to the DCR is mandatory in both Greenland and Denmark, and the coverage of the Cancer Registry in Denmark has shown to be $95-98 \%$ (Storm et al, 1997). Since 1975, the main source of information in the registry in Greenland has been notifications from physicians diagnosing and treating cancer patients, supplemented by the information obtained from pathology reports and death certificates. Information in the registry related to cancer cases in Greenland before 1975 was obtained from a study based on review of patient records from all hospitals in Greenland (Nielsen, 1986; Storm et al, 1997). The proportion of cases based on histological verification during the period 1973-1997 was 93 and 85\% in Denmark and Greenland, respectively (Friborg et al, 2003).

All gastric carcinomas diagnosed during the period 1973-2002 in individuals born in Greenland were identified in the Danish 
Cancer Register. The 145 cases thus found were screened using the Danish Pathology Database, and tumour material was identified in 117 and frequency matched with gastric carcinomas in individuals born in Denmark. For every Greenlandic case, the Danish gastric carcinomas of equivalent gender, age (10-year interval) and year of diagnosis (5-year interval) were identified using the Danish Civil Registry System and the Danish Cancer Register. All these potential controls were listed on the basis of a random number, and the first number was selected as the control. To reduce logistic effort, Danish controls $>40$ years of age were recruited from Aarhus County ( $\sim 650000$ inhabitants), whereas controls below 40 years were collected from all over Denmark ( $\sim 5.2$ million inhabitants). Paraffin-embedded tumour material was retrieved from pathology archives in 106 of 117 (90.6\%) Greenlandic cases and in 106 of 117 Danish controls, thus collecting a total of 212 samples for analysis. Of the remaining 22 samples, 12 could not be traced ( 5 cases and 7 controls), 4 were unsuitable for EBV analysis due to lack of tissue ( 3 cases and 1 control), 4 were excluded due to a non-gastric carcinoma diagnosis ( 2 cases and 2 controls) and in 2 cases only tumour material from metastases was available ( 1 case and 1 control).

All cases were reclassified by expert histopathologists according to the WHO 2000 guideline for the diagnosis of gastric carcinomas (International Agency for Research on Cancer (IARC), 2000), sub-classified according to the Laurén classification and re-staged (pTNM). The pathologist was blinded to EBV status and country of origin. From the results of the original pathology report, the macroscopic location of the tumours was determined as proximal (proximal $2 / 3$ of the stomach), distal (distal $1 / 3$ ) or diffuse. Gastric carcinoma cells in paraffin sections were analysed for the presence of EBV-latent membrane protein-1 and EBERs using immunohistochemistry with antibody cocktail CS 1-4 (Dako, Glostrup, Denmark) and RNA in situ hybridisation using the INFORM EBER probe (Ventana Medical Systems, Illkirch, France), respectively, as described (Zhou et al, 2001) with modifications. EBV-positive tonsils with infectious mononucleosis and lymph nodes with Hodgkin's lymphoma were used as positive controls. These methods represent the 'gold standard' for EBV analysis in tissue sections, and can be expected to detect the majority of virally infected tumours, even in archive paraffin blocks.

The associations between tumour characteristics, and ethnicity and EBV status were evaluated by $P$-values obtained from logistic regression. Adjustments were made for sex, age (10-year interval) and year at diagnosis (5-year interval). Trend tests for variables with ordered categories were conducted by assigning the values 1 , 2 and 3 to the ordered categories and by treating the variables as numerical in the regression analyses. A variation in the association between EBV-associated gastric carcinomas and ethnicity according to birth year was evaluated by tests for interaction. Significance level was set at 0.05 .

The study was approved by the Danish data protection board and by the appropriate scientific ethical committees in both countries.

\section{RESULTS}

We examined 212 gastric carcinomas, 106 from Greenland and 106 from Denmark, respectively, from 135 men (64\%) and 77 women $(36 \%)$. The average age at diagnosis was 55.1 (range: $26-78$ ) years among the Inuit and 55.8 (range: $22-79$ ) years among the matched Danes (Table 1). In both populations, the frequency of EBVassociated gastric carcinomas was $8.5 \%$ (9 of 106) (Table 2), representing an odds ratio (OR) of 1.0 (CI: 0.4-2.7). EBVassociated gastric carcinomas were more common among men (15 of $135=11.1 \%)$ compared with women (3 of $77=3.9 \%)$,
Table I The study population

\begin{tabular}{lcc}
\hline & Inuit $\mathbf{N}=\mathbf{1 0 6}$ & Danes $\mathbf{N}=\mathbf{1 0 6}$ \\
\hline Age at diagnosis (range) & $55.1(26-78)$ & $55.8(22-79)$ \\
Males/females & $68 / 38$ & $67 / 39$ \\
EBV positive (\%) & 8.5 & 8.5 \\
\hline
\end{tabular}

$\mathrm{EBV}=$ Epstein - Barr virus.

Table 2 Tumour characteristics of gastric carcinomas according to ethnicity

\begin{tabular}{|c|c|c|c|c|c|}
\hline & \multicolumn{2}{|c|}{ Inuit $n=106$} & \multicolumn{2}{|c|}{ Danes $n=106$} & \multirow[b]{2}{*}{$P$-value } \\
\hline & $N$ & $\%$ & $\mathbf{N}$ & $\%$ & \\
\hline \multicolumn{5}{|l|}{ EBV status } & 0.99 \\
\hline EBV-positive gastric carcinoma & 9 & 8.5 & 9 & 8.5 & \\
\hline EBV-negative gastric carcinoma & 97 & 91.5 & 97 & 91.5 & \\
\hline \multicolumn{5}{|l|}{ Material } & 0.48 \\
\hline Biopsy & 42 & 39.6 & 38 & 35.8 & \\
\hline Gastrectomy specimens & 64 & 60.4 & 68 & 64.2 & \\
\hline \multicolumn{5}{|l|}{ Location } & $0.005^{\mathrm{a}}$ \\
\hline Proximal & 25 & 23.6 & 40 & 37.7 & \\
\hline Distal & 55 & 51.9 & 37 & 34.9 & \\
\hline Diffuse & 5 & 4.7 & 11 & 10.4 & \\
\hline Unknown & 21 & 19.8 & 18 & 17.0 & \\
\hline \multicolumn{5}{|l|}{ Histology (WHO) } & $0.24^{b}$ \\
\hline Papillary & 3 & 2.8 & 3 & 2.8 & \\
\hline Tubular & 71 & 67.0 & 63 & 59.4 & \\
\hline Mucinous & 4 & 3.8 & । & 0.9 & \\
\hline Signet-ring cell & 20 & 18.9 & 25 & 23.6 & \\
\hline Undifferentiated & 7 & 6.6 & 13 & 12.3 & \\
\hline Adenosquamous & i & 0.9 & । & 0.9 & \\
\hline \multicolumn{5}{|l|}{ Histology (Laurén) } & $0.27^{c}$ \\
\hline Intestinal & 72 & 67.9 & 67 & 63.2 & \\
\hline Diffuse & 31 & 29.2 & 39 & 36.8 & \\
\hline Mixed & 3 & 2.8 & 0 & 0 & \\
\hline \multicolumn{5}{|c|}{ Differentiation of tubular type carcinomas } & $0.25^{\mathrm{d}}$ \\
\hline Good & 11 & 15.5 & 6 & 9.5 & \\
\hline Moderate & 37 & 52.1 & 31 & 49.2 & \\
\hline Poor & 23 & 32.4 & 26 & 41.2 & \\
\hline \multicolumn{5}{|l|}{ Degree of lymphocyte infiltration } & $0.07^{d}$ \\
\hline Low & 54 & 50.9 & 65 & 61.3 & \\
\hline Moderate & 46 & 43.4 & 38 & 35.8 & \\
\hline Abundant & 6 & 5.7 & 3 & 2.8 & \\
\hline \multicolumn{5}{|l|}{ Pattern of lymphocyte infiltration } & $0.99^{\mathrm{e}}$ \\
\hline Lymphoepithelioma-like & 0 & 0 & 0 & 0 & \\
\hline Nodular & 22 & 20.7 & 22 & 20.7 & \\
\hline Diffuse & 80 & 75.5 & 84 & 79.2 & \\
\hline Follicular infiltration & 4 & 3.8 & 0 & 0 & \\
\hline
\end{tabular}

$\mathrm{EBV}=$ Epstein - Barr virus; $\mathrm{WHO}=$ World Health Organisation. Tubular adenocarcinomas were categorised as well differentiated (well-formed glands), moderately differentiated (intermediate between well differentiated and poorly differentiated) and poorly differentiated (highly irregular glands that are recognised with difficulty or single cells that remain isolated or are arranged in small clusters) according to WHO 2000. The pattern and degree of lymphocytic infiltration was assessed semiquantitatively as either absent, mild, moderate or abundant infiltration by examining 10 medium power fields ( $\times 200$ magnification). The pattern of lymphocyte infiltration was determined as lymphoepithelioma-like, nodular, diffuse or follicular. aNon-distal vs distal location, samples with 'unknown' location not included. ' ${ }^{\mathrm{T}}$ Tubular histology vs other types. 'Samples with 'mixed' histology not included. ' $P$-value

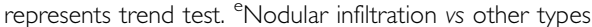


Table 3 Tumour characteristics of gastric carcinoma according to EBV status

\begin{tabular}{|c|c|c|c|c|c|}
\hline & \multicolumn{2}{|c|}{$\begin{array}{c}\text { EBV-positive } \\
\text { gastric carcinoma } \\
\qquad n=18\end{array}$} & \multicolumn{2}{|c|}{$\begin{array}{c}\text { EBV-negative } \\
\text { gastric carcinoma } \\
\qquad n=194\end{array}$} & \multirow[b]{2}{*}{$P$-value } \\
\hline & $\mathbf{N}$ & $\%$ & $\mathbf{N}$ & $\%$ & \\
\hline Gender & & & & & 0.19 \\
\hline Males & 15 & 83 & 120 & 62 & \\
\hline Females & 3 & 17 & 74 & 38 & \\
\hline Material & & & & & 0.98 \\
\hline Biopsy & 8 & 44.4 & 72 & 37.1 & \\
\hline Gastrectomy specimens & 10 & 55.6 & 122 & 62.9 & \\
\hline Location & & & & & $0.33^{\mathrm{a}}$ \\
\hline Proximal & 6 & 33.3 & 59 & 30.4 & \\
\hline Distal & 6 & 33.3 & 86 & 44.3 & \\
\hline Diffuse & 2 & 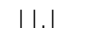 & 14 & 7.2 & \\
\hline Unknown & 4 & 22.2 & 35 & 18.0 & \\
\hline Histology (WHO) & & & & & $0.12^{b}$ \\
\hline Papillary & 0 & 0 & 6 & 3.1 & \\
\hline Tubular & 15 & 83.3 & 119 & 61.3 & \\
\hline Mucinous & 0 & 0 & 5 & 2.6 & \\
\hline Signet-ring cell & I & 5.6 & 44 & 22.7 & \\
\hline Undifferentiated & 2 & $|1|$. & 18 & 9.3 & \\
\hline Adenosquamous & 0 & 0 & 2 & 1.0 & \\
\hline Histology (Laurén) & & & & & $0.23^{c}$ \\
\hline Intestinal & 14 & 77.8 & 125 & 64.4 & \\
\hline Diffuse & 3 & 16.7 & 67 & 34.5 & \\
\hline Mixed & 1 & 5.6 & 2 & 1.0 & \\
\hline $\begin{array}{l}\text { Differentiation of tubular } \\
\text { type carcinomas }\end{array}$ & & & & & $0.24^{d}$ \\
\hline Good & 0 & 0 & 17 & 14.3 & \\
\hline Moderate & 9 & 60.0 & 59 & 49.6 & \\
\hline Poor & 6 & 40.0 & 43 & 36.1 & \\
\hline $\begin{array}{l}\text { Degree of lymphocyte } \\
\text { infiltration }\end{array}$ & & & & & $0.03^{d}$ \\
\hline Low & 6 & 33.3 & 113 & 58.2 & \\
\hline Moderate & 9 & 50.0 & 75 & 38.7 & \\
\hline Abundant & 3 & 16.7 & 6 & 3.1 & \\
\hline $\begin{array}{l}\text { Pattern of lymphocyte } \\
\text { infiltration }\end{array}$ & & & & & $0.60^{\mathrm{e}}$ \\
\hline Lymphoepithelioma-like & 0 & 0 & 0 & 0 & \\
\hline Nodular & 3 & 16.7 & 41 & 21.1 & \\
\hline Diffuse & 15 & 83.3 & 149 & 76.8 & \\
\hline Follicular infiltration & 0 & 0 & 4 & 2.1 & \\
\hline
\end{tabular}

$\mathrm{EBV}=$ Epstein - Barr virus; $\mathrm{WHO}=$ World Health Organisation; Tubular adenocarcinomas were categorised as well differentiated (well-formed glands), moderately differentiated (intermediate between well differentiated and poorly differentiated) and poorly differentiated (highly irregular glands that are recognised with difficulty or single cells that remain isolated or are arranged in small clusters) according to $\mathrm{WHO}$ 2000. The pattern and degree of lymphocytic infiltration was assessed semiquantitatively as absent, mild, moderate or abundant infiltration by examining 10 medium power fields ( $\times 200$ magnification). The pattern of lymphocyte infiltration was determined as lymphoepithelioma-like, nodular, diffuse or follicular. ${ }^{a}$ Non-distal vs distal location, samples with 'unknown' location not included. 'Tubular histology vs other types. 'Samples with 'mixed' histology not included. ${ }^{d} P$-value represents trend test. 'Nodular infiltration vs other types.

$(P=0.19, \mathrm{OR}=2.44 ; \mathrm{CI}: 0.64-9.37)$ (Table 3$).$ The associations between tumour characteristics, and ethnicity and EBV status are summarised in Tables 2 and 3. The EBV status was not associated with tumour location, but a distal location was more frequent among the Inuit $(P=0.005 ; \mathrm{OR}=0.40 ; \mathrm{CI}: 0.21-0.76)$. Although the degree of lymphocytic infiltration was most frequently 'low' (119 of 212), it was significantly higher in EBV-associated gastric carcinomas than in non-EBV-associated gastric carcinomas $(P=0.03$; OR 2.36; CI 1.07-5.22). Tumour histology (WHO/ Laurén) was not related to EBV status or ethnicity. Although undifferentiated gastric carcinomas were identified in patients from both Greenland and Denmark, none were of the lymphoepithelial type. We observed no temporal changes in either the proportion of EBV-GC or in the tumour location over the period (data not shown). The risk of having EBV-associated gastric carcinomas was not related to ethnicity; but the Inuit with EBVpositive cases were born earlier than the Danes with such tumours $(P<0.01)$ (data not shown).

\section{DISCUSSION}

We found an equal proportion of EBV-associated gastric carcinomas in the Inuit and Danes, suggesting that the factors responsible for the high incidence of EBV-positive NPC and salivary gland carcinoma in Greenland do not influence the risk of EBV-associated gastric carcinomas.

The risk of NPC and salivary gland carcinoma are strikingly higher among the Inuit in Greenland compared with the Danes in Denmark, with standardised incidence ratios of $\sim 35$ and 6, respectively (Friborg et al, 2003). There is also a clear increased familial risk of NPC and salivary gland carcinoma among the Inuit, with an eight-fold increased risk in first-degree relatives, which is among the highest reported for any cancer (Goldgar et al, 1994; Friborg et al, 2005). These high risks imply the existence of strong genetic or environmental risk factors for EBV-associated NPC and salivary gland carcinoma in the Inuit population. However, the similar proportion of EBV-associated gastric carcinomas in Greenland and Denmark argues against a general susceptibility to EBV-associated carcinomas among the Inuit. EBV-associated carcinomas of the nasopharynx and salivary glands in the Inuit are mainly of the lymphoepithelial type (Nielsen, 1986). It must be noted that, we did not identify an increased incidence of gastric carcinomas of this histopathological type in Greenland.

The proportion of EBV-associated gastric carcinomas in Greenland and Denmark (8.5\%) is comparable with frequencies found worldwide (IARC working group, 1997; Burgess et al, 2002; Hjalgrim et al, 2008). Studies of EBV positivity in gastric carcinomas have produced varied results, with prevalence ranging from 2 to $15 \%$. Some of this variation may be attributed to differences in sample collection and EBV detection. The advantages of our study include a population-based case collection, and optimal, uniform methods for EBV detection.

We did not find an increased proportion of EBV-associated gastric carcinomas in Greenland, a high-incidence region for other EBV-associated carcinomas, arguing against a general susceptibility to EBV-associated carcinomas among the Inuit.

\section{ACKNOWLEDGEMENTS}

This work was supported by the Danish Cancer Society [DP04102], the Danish Medical Research Council [220-04-0441] and the Lundbeck Foundation [R7-A695-B558].

The authors thank Kristina Lystlund Lauridsen, Institute of Pathology, Aarhus University Hospital, for laboratory assistance. 


\section{REFERENCES}

Alberts SR, Kelly JJ, Lanier AP, Sacco F (2006) Occurrence of esophageal and gastric cancer in Alaska natives, 1969-2003. Alaska Med 48: 2-11

Burgess DE, Woodman CB, Flavell KJ, Rowlands DC, Crocker J, Scott K, Biddulph JP, Young LS, Murray PG (2002) Low prevalence of EpsteinBarr virus in incident gastric adenocarcinomas from the United Kingdom. Br J Cancer 86: $702-704$

Friborg J, Koch A, Wohlfarht J, Storm HH, Melbye M (2003) Cancer in Greenlandic Inuit 1973 - 1997: a cohort study. Int J Cancer 107: 1017 - 1022

Friborg J, Wohlfahrt J, Koch A, Storm H, Olsen OR, Melbye M (2005) Cancer susceptibility in nasopharyngeal carcinoma families - a population-based cohort study. Cancer Res 65: 8567-8572

Goldgar DE, Easton DF, Cannon-Albright LA, Skolnick MH (1994) Systematic population-based assessment of cancer risk in first-degree relatives of cancer probands. J Natl Cancer Inst 86: 1600-1608

Hamilton-Dutoit SJ, Therkildsen MH, Neilsen NH, Jensen H, Hansen JP, Pallesen G (1991) Undifferentiated carcinoma of the salivary gland in Greenlandic Eskimos: demonstration of Epstein-Barr virus DNA by in situ nucleic acid hybridization. Hum Pathol 22: 811-815

Hao Z, Koriyama C, Akiba S, Li J, Luo X, Itoh T, Eizuru Y, Zou J (2002) The Epstein-Barr virus-associated gastric carcinoma in Southern and Northern China. Oncol Rep 9: 1293-1298

Hjalgrim H, Friborg J, Melbye M (2008) In Human Herpesviruses - Biology, Therapy, and Immunoprophylaxis, Arvin, Campadelli-Fiume, Mocarski, Moore, Roizman, Whitley, Yamanishi (eds) pp 947-948. Cambridge University Press: Cambridge
IARC working group (1997) Epstein-Barr Virus and Kaposi's Sarcoma Herpesvirus/Human Herpesvirus 8. World Health Organization Internationl Agency for Research on Cancer: Lyon

Imai S, Koizumi S, Sugiura M, Tokunaga M, Uemura Y, Yamamoto N, Tanaka S, Sato E, Osato T (1994) Gastric carcinoma: monoclonal epithelial malignant cells expressing Epstein-Barr virus latent infection protein. Proc Natl Acad Sci USA 91: 9131 -9135

International Agency for Research on Cancer (IARC) (2000) Pathology and genetics of tumours of the digestive system. In: International Agency for Research on Cancer (IARC) Stanley R. Hamilton and Lauri A. Aaltonen (eds) pp 35-52. World Health Organization Classification of Tumours: Lyon

Nielsen NH (1986) Cancer incidence in Greenland. Arctic Med Res 43: $1-168$

Parkin DM, Bray F, Ferlay J, Pisani P (2005) Global cancer statistics, 2002. CA Cancer J Clin 55: 74-108

Shibata D, Weiss LM (1992) Epstein-Barr virus-associated gastric adenocarcinoma. Am J Pathol 140: $769-774$

Storm HH, Michelsen EV, Clemmensen IH, Pihl J (1997) The Danish Cancer Registry - history, content, quality and use. Dan Med Bull 44: $535-539$

Zhou XG, Sandvej K, Li PJ, Ji XL, Yan QH, Zhang XP, Da JP, HamiltonDutoit SJ (2001) Epstein-Barr virus (EBV) in Chinese pediatric Hodgkin disease: Hodgkin disease in young children is an EBV-related lymphoma. Cancer 92: $1621-1631$ 